\title{
O REALISMO-NATURALISMO DE STENDHAL E SHIMAZAKI TÔSON. UMA ANÁLISE PSICOLÓGICA DAS PERSONAGENS CENTRAIS: JULIEN E USHIMATSU
}

Monica Setuyo Okamoto

\begin{abstract}
Resumo: Este artigo enfoca, de forma comparativa, as personagens centrais das obras Hakai (1906) do escritor japonês Shimazaki Tôson (1872-1943) e O Vermelho e o Negro (Le Rouge et Le Noir, 1830) do realista francês Stendhal. Embora o Realismo-Naturalismo japonês tenha recebido maior influência de Guy de Maupassant e dos autores alemães, notamos grandes similitudes entre as obras de Tôson e Stendhal, as quais serão expostas neste artigo. Ressaltamos, porém, que o estudo comparativo aqui será restrito à análise do papel social e do perfil psicológico das duas personagens, Ushimatsu e Julien, dentro de seus respectivos contextos históricos; sem a intenção, portanto, de abordar outros aspectos das duas obras.
\end{abstract}

Palavras-chave: Realismo-Naturalismo, Stendhal, Shimazaki Tôson, Hakai, O Vermelho e o Negro.

Abstract: This article focuses, comparatively, the central characters of books Hakai (The Broken Commandment, 1906) Japanese writer Shimazaki Tōson and Le Rouge et le Noir (The Red and the Black, 1830) of the French realist Stendhal. Although the Japanese Realism-Naturalism received greater influence of Guy de Maupassant and German authors, noted many similarities between the works of Stendhal and Tōson which will be exposed in this article. We emphasize, however, that the comparative study here will be restricted to the analysis of social role and psychological profile of the two characters, Ushimatsu and Julien, within their respective historical contexts, without the intention, therefore, to address other aspects of the two works.

Keywords: Realism-Naturalism, Stendhal, Shimazaki Tôson, Hakai, The Red and the Black.

O final do período Meiji (1868-1912) foi marcado pelo auge e declínio do Realismo-Naturalismo japonês, quando a influência estrangeira se fez presente, particularmente a francesa. Aliás, a palavra Shizenshugi é uma tradução literal do 
termo francês Naturalisme, porém, apesar de a palavra francesa ter sido incorporada na sua integridade, o seu conteúdo sofreu algumas modificações e adaptações à cultura e ao momento histórico japonês.

Este artigo tem como intenção apresentar uma análise crítico/comparativa entre as obras realista-naturalista de Shimazaki Tôson e Stendhal. Frisamos que devido às fronteiras imprecisas entre o Realismo e o Naturalismo, optou-se pela junção das duas como fazem alguns críticos literários. No caso do Japão, a entrada dessas duas Escolas foi quase que concomitante o que acabou resultando num hibridismo dos dois movimentos literários dentro da literatura japonesa.

Os realistas-naturalistas franceses formaram o Groupe de Médan, que teve como figura de destaque o polêmico jornalista, crítico de arte e escritor Émile Zola (1840-1902). Os membros do grupo foram considerados como sendo a segunda geração dos realistas. A teoria literária realista-naturalista francesa foi praticamente toda formulada pelo autor de Nana e, por conseguinte, a França foi considerada o berço do Realismo-Naturalismo. Esse movimento literário francês foi introduzido em diversas partes do mundo e em diferentes épocas, fato que ocasionou a inevitável adaptação e reformulação de algumas ideias às tradições e ao contexto histórico de cada país. Tal foi o caso do Japão, como veremos a seguir.

\section{O Realismo-Naturalismo japonês}

Tsubouchi Shôyô foi um renomado literato que mostrou a sua versatilidade como crítico literário, educador, escritor e tradutor. Segundo Donald Keene (1984), foi o introdutor do Realismo no Japão e era um grande apreciador de Shakespeare. Sua obra teórica Shôsetsu Shinzui (A Essência do Romance, 1885) é composta por dois volumes, sendo que no primeiro, Tsubouchi expõe os princípios fundamentais do romance, enquanto que no segundo, o autor aborda a metodologia. Basicamente, o livro trata da evolução literária e da necessidade de empregar o realismo nos romances, já que, para ele, a literatura não pode ser tratada como uma arte independente, pois deve estar sempre ligada aos objetivos práticos da vida. Seu realismo era baseado em observações objetivas e descrições da vida e o princípio fundamental do romance estava centrado na natureza humana, sendo todo o restante secundário.

Já Futabatei Shimei, discípulo de Tsubouchi, escreveu o primeiro romance realista do período Meiji, intitulada Ukigumo (O Movimento das Nuvens, 1887), baseada na teoria de seu mestre. Futabatei foi um grande estudioso da literatura russa e admirador de Turgeniev. Realizou várias traduções de obras russas, chegando inclusive a aplicar o que o autor chamava de método objetivo de tradução, ou seja, tentava reproduzir não só a ideia original da obra, mas também cada vírgula e ponto da sentença. O motivo de seu interesse pela literatura russa 
estava ligado a questões diplomáticas entre os dois países que se encontravam em conflito na época.

Mas o Realismo-Naturalismo japonês atingiu a sua fase áurea logo após o fim da guerra contra a Rússia (1904-1905) e, certamente, não foi por acaso. Os japoneses acreditavam que a vitória marcaria o ingresso do Japão na vida internacional, contudo, apesar dos louros da conquista e do respeito das potências ocidentais, os nipônicos ficaram desapontados com os injustos Tratados de Paz estipulados pelos países poderosos: Inglaterra, França, Estados Unidos e Alemanha. Essas nações, que criticavam os horrores cometidos durante a guerra russo-japonesa, também se mantinham nos bastidores tentando tirar algum proveito dela. O clima de revolta, injustiça e pessimismo era geral no Japão, levando a se designar o período pós-guerra como o "Ano da desilusão". Toda essa situação não poderia passar despercebida pelos escritores japoneses da época que, contagiados pelo momento histórico, passaram a buscar uma nova visão de mundo mais centrada na realidade, mais empírica e, consequentemente, menos romântica e ilusória.

Foi nesse clima que o Realismo-Naturalismo japonês floresceu em sua totalidade. Como se sabe, o Japão importou da França os pressupostos básicos do Realismo-Naturalismo, porém, em alguns aspectos, observa-se que a teoria de Zola adquiriu uma nova roupagem. Vale lembrar que o calor do movimento literário já havia se extinguido na França há quase vinte anos, quando este foi introduzido no Japão. Notamos, por exemplo, que os temas sociais como a brutalidade, a prostituição, o alcoolismo e a promiscuidade sexual foram tratados de maneira mais cândida nos romances nipônicos. A partir do ponto de vista da diferença cultural, destacamos que esse fato não foi aleatório, simplesmente porque os japoneses têm uma concepção diferente desses temas em comparação com a acepção ocidental. Naquela época, muitas mulheres japonesas eram vendidas à casa de prostituição, pela própria família ou até mesmo pelo marido, decorrentes de problemas financeiros. Naturalmente, isso não deixava de ser um problema social, porém a imagem da gueixa estava bem distante da imagem da prostituta ocidental. As gueixas, vendidas nessas circunstâncias, eram motivo de respeito para a família e para o marido que reconheciam o sacrifício da pobre mulher em prol do bem-estar de seus familiares. Quanto à brutalidade e ao alcoolismo eram características quase inerentes ao espírito nipônico recém-saído do sistema xogunal, no qual a bravura e a força dos samurais tinham que ser constantemente reafirmadas como demonstração de sua coragem e virilidade.

A visão capitalista também foi mais amena entre os escritores realistas-naturalistas japoneses, pois, apesar de eles se basearem no princípio da causalidade, ou seja, no desenvolvimento natural do enredo, na eliminação do acaso e dos milagres e na descrição do ambiente de acordo com as condições e motivos, não observamos, com muita frequência, o pensamento tecnológico e científico sobre 
o espírito tradicional japonês. Por outro lado, os autores franceses retrataram a nova sociedade transformada, criticando os valores da burguesia e o sistema político capitalista; além disso, desprezaram o neoclassicismo romântico que possuía intensa ligação com a Igreja e a Monarquia.

Outra diferença é que o Realismo-Naturalismo no Japão não teve seus territórios rigidamente delimitados, pois, na realidade, muitos consideram o Naturalismo japonês uma extensão do impulso dado pelo Realismo de Tsubouchi Shôyô. Uma peculiaridade do movimento japonês encontra-se no fato de que a maioria de seus escritores era originária da casta inferior dos samurais, o que facilitou, para eles, a produção de obras com uma linguagem mais popular.

Segundo Donald Keene (1984), a primeira apresentação do RealismoNaturalismo francês no Japão foi feita pelo escritor Mori Ôgai em seu artigo de 1889, no qual trata da obra de Zola e sua relação com a medicina experimental de Claude Bernard. Ôgai, apesar de médico, desaprova essa fusão entre a medicina e a ficção e, em seus artigos posteriores, continuou criticando o realismo exacerbado de Zola que, segundo o crítico japonês, pecava pelos seus temas imorais e obscenos. Percebemos, dessa maneira, que as obras de Zola, fora do contexto histórico e social da França, foram incompreendidas por muitos escritores e por grande parte do público nipônico. Curiosamente, a figura de Guy de Maupassant acabou se tornando muito mais popular que a de Zola no Japão. É preciso esclarecer que, inicialmente, Maupassant começou a sua carreira literária sendo membro do Groupe de Médan, realistas-naturalistas liderados por Zola, mas rompeu com a estética do autor de Germinal, produzindo textos mais próximos de Flaubert, seu mestre.

O escritor Tayama Katai conta como começou a sua adoração por Maupassant em seu livro Literary Life in Tokyo (1987). Segundo ele, foi quando comprou a coleção Contos de Maupassant, em 12 volumes, e sentiu um enorme prazer em saber que era a primeira pessoa no Japão a ler essa obra. Katai ainda revela que passou a compreender melhor os escritores japoneses, após as suas leituras de obras ocidentais, particularmente Zola, Maupassant, Nietzsche, Tolstoi e Flaubert. A leitura das obras desses escritores ocidentais, eleitos por muitos literatos e intelectuais japoneses da época como paradigmas culturais, auxiliou Tayama Katai a perceber a diferença entre um ficcionista que descreve incidentes e um escritor que retrata o lado psicológico de suas personagens.

A primeira obra realista-naturalista japonesa (ou simplesmente naturalista, como apontam alguns críticos nipônicos) foi Hatsusugata (Primeiro Uso do Quimono no Ano Novo, 1900), de Kosugi Tengai, considerado pioneiro na introdução da teoria de Zola no Japão. Tengai conheceu os trabalhos de Zola em 1896 e passou a escrever produzindo descrições mais objetivas. No prefácio de Hatsusugata, o escritor japonês esclarece que não escreve com intenções de agradar a si próprio, muito menos os críticos ou leitores (essa postura é idêntica à de 
Zola, que também não estava interessado em agradar ao seu público com romances melosos ou ditos moralizantes).

Outro escritor que recebeu grande influência de Zola e Maupassant foi Kunikida Doppo. Filho ilegítimo de um samurai e de uma criada estudou literatura inglesa na Universidade de Waseda e também, como Kosugi Tengai, tinha intenções de ser político, mas a promulgação da Constituição Meiji em 1890 acabou com seus sonhos românticos. Sua desilusão com a política o levou ao caminho do Cristianismo e da literatura. Passa a escrever as biografias de Benjamin Franklin e Abraham Lincoln, acreditando que essas duas figuras distintas da política ocidental poderiam inspirar os jovens nipônicos.

Doppo foi basicamente um romântico no início de sua carreira, entretanto, após sofrer desapontamentos na vida profissional e amorosa, revela um caráter mais pessimista, de resignação diante das misérias humanas que, em sua opinião, estão ligadas ao fator hereditário.

Mas, dentre todos esses escritores japoneses, o mais representativo desse período foi sem dúvida Shimazaki Tôson, autor de Hakai, que foi qualificado, por Natsume Sôseki, como o primeiro romance de valor do período Meiji (1868-1912). $\mathrm{Na}$ verdade, essa obra teve início em 1899, quando Tôson deixa a capital para lecionar numa escola secundária de Komoro, uma pequena cidade da província de Nagano, no Japão. Passa anos fazendo anotações do local em seu caderno de observações e retorna a Tóquio em 1905, quando toma contato, novamente, com a literatura realista-naturalista francesa. Esse fato foi decisivo na produção de $\mathrm{Hakai}$, que foi lançado em março do ano seguinte. Para a surpresa de todos, inclusive do escritor, dez dias após a primeira publicação da obra, foi feito um novo pedido para a segunda publicação. O sucesso foi significativo e, desde então, o termo Realismo/Naturalismo passou a ser divulgado nos jornais e nas revistas japonesas.

À medida que nos aproximamos do final do período Meiji, notamos a presença da literatura francesa no meio literário japonês. Como não poderia deixar de ser, o Japão também tomou a França, sob certos aspectos, como modelo de civilização e cultura. Esclarecemos que por se tratar de um assunto extenso e complexo, serão relatados a seguir apenas os principais acontecimentos desse período, bem como serão expostos os pressupostos fundamentais dessa escola literária, uma vez que o nosso objetivo não é o de percorrer todos os caminhos do movimento realista-naturalista, mas apresentar apenas um esboço histórico-literário.

\section{O Realismo-Naturalismo francês}

Até o século XVIII, os escritores franceses escreviam para um único público, a aristocracia. Entretanto, após a Revolução Francesa (1789), surge uma nova classe de leitores, a burguesia que tomou o poder, mas que conservou o método 
administrativo da velha aristocracia. Munida de poder e dinheiro, a sociedade burguesa imperou inabalável até a segunda metade do século XIX, quando tem o início a luta da classe proletária pela conquista de reformas sociais. A literatura e as artes sofreram uma terrível degradação por estarem atreladas ao gosto de seu novo público. A literatura passa a ser um simples entretenimento, leituras fáceis e agradáveis, e a arte cumpria uma função unicamente decorativa. Contudo, depois da Revolução de 1830, nasce uma nova consciência de classe entre os proletários que retomam as reivindicações esquecidas após a Revolução Francesa.

Os romances de Stendhal e Balzac são as primeiras obras que tratam da vida real, das suas dificuldades, dos seus problemas e dos seus conflitos morais. Eles causaram o primeiro abalo no conservador público romântico ao transformarem em herois, pessoas comuns e de origem plebeia. A diferença básica entre Stendhal e Balzac é que o primeiro foi um crítico conservador, enquanto o outro, um liberal. Stendhal acredita na volta da cultura iluminista que, a seu ver, reflete um mundo exemplar, já Balzac considera que esse mundo já se desintegrou diante do progresso do capitalismo e que a moderna sociedade burguesa e a ganância pelo dinheiro são os grandes males de seu tempo e a única salvação estava na Monarquia e na Igreja Católica. Sua crítica está voltada aos ideais e ao comportamento da sociedade tanto burguesa quanto proletária, que, em sua visão, lutam pelas mesmas ambições: lucros e privilégios.

A moderna sociedade capitalista, os avanços tecnológicos e científicos, o racionalismo econômico, os acontecimentos políticos e sociais da primeira metade do século XIX são alguns dos fatores que deram início a uma campanha contra o Romantismo. Por volta da década de 1850 , os ideais românticos estavam cada vez mais desgastados com a evolução do pensamento ocidental e o desenvolvimento científico. O mundo real era mesquinho e injusto e todos se cansaram dos sonhos e tentaram buscar o conhecimento exato da realidade no espírito científico.

Alguns românticos tentaram manter-se no meio literário criando uma redoma de vidro, isto é, procuraram refúgio no individualismo, na l'art pour l'art. Um dos seguidores dessa teoria foi o escritor realista Gustave Flaubert (1821-1880), cujas obras, em especial Madame Bovary (1857), numa primeira leitura leva o leitor a acreditar que a sua intenção seja a de passar uma visão ideológica a respeito da vida burguesa; porém uma leitura mais atenta nos leva a perceber que o autor de Educação Sentimental procura apenas reproduzir mimeticamente a realidade que é sua contemporânea, de forma impessoal e apartidária.

Maupassant concorda com Flaubert a respeito da impessoalidade do autor na arte, cujo objetivo maior é o de reproduzir a realidade, sem qualquer vestígio ou opinião do autor, porém sem deixar de lado a forma.

É imprescindível esclarecer que a distinção entre Realismo e Naturalismo é bastante sutil, tanto que muitos críticos costumam agrupar os dois termos e, em 
alguns casos, incluem o Impressionismo no caos terminológico. Seja como for, o movimento realista foi anticlerical, antirromântico, racionalista, adepto do objetivismo, republicano, determinista e cientificista. Segundo Arnold Hauser (1971), a diferença básica entre o Realismo e o Naturalismo está no princípio desses dois movimentos. O Realismo prega uma filosofia oposta ao Romantismo e ao seu idealismo exacerbado, ao passo que o Naturalismo apresenta-se mais como movimento artístico da massa, ou seja, dirige-se ao povo, mostra suas feridas abertas e antipatiza-se com a mediocridade da sociedade burguesa.

Gustave Flaubert apresenta, por exemplo, a hipocrisia romântica e a degradação do estilo de vida e pensamento burguês em sua obra Madame Bovary, ao passo que os irmãos Edmond e Jules de Goncourt protestam, em Germinie Lacerteux (1864), contra o descaso dado às camadas mais baixas nas ficções. Nos romances de Stendhal, Balzac e Flaubert, o proletariado é praticamente ignorado, mas na obra dos irmãos Goncourt as classes mais humildes ganham destaque e o direito de participarem, de forma ativa, no romance.

Já Otto Maria Carpeaux (1963) não acredita que a única diferença entre o Realismo e o Naturalismo francês seja o grau de "radicalismo sociológico." A seu ver, "na evolução percorrida do realismo ao naturalismo, devem ter agido outras influências mais do que o radicalismo sociológico.” (p. 2261).

Para compreender melhor a visão realista-naturalista, tanto na arte como na literatura, é imprescindível o conhecimento das principais correntes filosóficas e científicas do século XIX, as quais se mostram fundamentais para a formação desse movimento.

Historicamente, a Revolução Industrial significou um período de grandes transformações sociais e econômicas em vista do espantoso progresso tecnológico e científico que impulsionou o crescimento urbano e a instalação de fábricas. Não obstante todo esse incremento, cresce a revolta social diante da mecanização do trabalho humano e da miséria das massas, que passam a se organizar em sindicatos e a reivindicar seus direitos.

Um dos escritores do Realismo/Naturalismo francês que melhor descreveu as péssimas condições da classe dos trabalhadores foi Émile Zola. Em Germinal (1885), por exemplo, o tema central são as greves e as revoltas do proletariado. Já em L'Assomoir (1877), o autor trata da miséria da vida humana degradada pelo álcool e pela pobreza. Denunciou também as desigualdades sociais do capitalismo em Au Bonheur des Dames (1883), e a ganância pelo dinheiro e pelo poder em L'Argent (1891). Esse foi o quadro social que compôs as obras realistas-naturalistas, sobretudo francesas, as quais foram taxadas, pelos conservadores, de imorais, vulgares, mórbidas e obscenas.

Esse movimento literário e artístico intimamente ligado à Revolução Industrial e às suas consequências chamou a atenção para a mudança de valores 
da sociedade, cada vez mais concentrada nos aspectos externos e nos elementos materiais da vida. O progresso das ciências, nesse período, também contribuiu para a revolução de pensamentos e crenças sedimentados, como foi o caso da publicação, em 1859, da Origin of Species, formulada pelo teórico evolucionista Charles Darwin. Ele parte do princípio de que o homem é descendente dos animais e que, na luta pela existência, a natureza e o meio ambiente selecionam os mais fortes para a sobrevivência e reprodução, por um processo de seleção natural. A teoria de Darwin destruiu o orgulho aristocrático e divergiu, frontalmente, de todos os ensinamentos da Igreja Católica.

O filósofo inglês Herbert Spencer (1820-1903), com base na teoria darwinista, acrescentou a ideia da "sobrevivência dos mais aptos" e defendeu, consequentemente, o individualismo. Da mesma forma, Augusto Comte também aproveitou o impulso dado pela teoria evolucionista para formular o Positivismo filosófico, sistema que lançou a ideia de causa e efeito, ou seja, o único meio válido para se atingir o conhecimento humano é por meio do método científico de pensamento. Essa aplicação do método científico ao estudo do homem é claramente visível na teoria dos realistas-naturalistas, que costumavam realizar análises microscópicas, dissecando o comportamento humano. Dessa maneira, podemos constatar que a doutrina naturalista parte do pressuposto de que o homem não passa de um animal, determinado pela hereditariedade, meio e momento histórico.

Os realistas-naturalistas se aproveitam desse fundamento científico (no qual o homem é reduzido ao mesmo nível dos animais inferiores, em contraste com o homem idealizado do período romântico) para provar que o ser humano, em momentos extremos de pressão e crise, traz à tona a sua brutalidade primitiva, revelando o seu lado irracional e selvagem. Assim, percebemos que os realistas-naturalistas foram mais ácidos que os evolucionistas, ao tentarem inverter o processo de evolução do homem, ou seja, acreditam que o homem nunca evoluiu, pois em momentos extremos o seu lado irracional estará sempre latente. Essa degeneração humana pode ser constatada na obra L'Assomoir, de Zola.

Erich Auerbach, em Mimesis (1971), dedica um capítulo (intitulado "Germinie Lacerteux") à análise do prefácio da obra dos irmãos Goncourt. Segundo Auerbach, a atração dos autores pelo feio e pelo patológico é apontada logo no prefácio de I Germinie Lacerteux, no qual advertem o leitor para “(...) que não espere a fotográfica decotada do Prazer: o estudo que segue é a clínica do amor" (p. 432) e que se trata de um romance verdadeiro (ataque ao subjetivismo e ao idealismo românticos que fazem o público apreciar romances "falsos"). O autor de Mimesis prossegue sua análise e fala da intenção dos irmãos Goncourt em provocar uma tensão entre escritor e leitor, entre a expectativa do público (o que ele gosta, espera e a que está acostumado) e a obra que contraria os hábitos e perturba a higiene. Em outras palavras, criticam o gosto do leitor burguês que 
toma a arte apenas como um entretenimento e que, portanto, encontra-se alienado dos problemas da sociedade contemporânea. Ao lermos o polêmico prefácio notamos também que, na visão desses dois irmãos, as obras românticas tornaram os leitores insensíveis a qualquer questão que não estivesse vinculada ao repertório sociocultural burguês. O autor de Mimesis esclarece também que a maior parte dos leitores daquela época pertencia à burguesia, portanto as revistas e os jornais, que eram os principais divulgadores dos trabalhos de literatura e de arte, priorizavam o lucro em detrimento da cultura, ou seja, publicavam apenas aquilo que era de agrado de seu público.

Émile Zola, considerado o pai do Realismo-Naturalismo, cronologicamente posterior à geração de Flaubert e Goncourt, sofreu grande influência deles. Sua pretensão era a de apresentar um retrato verdadeiro da sociedade contemporânea, sem a preocupação de procurar agradar ao seu público. Fez das doenças sociais de sua época os temas de suas obras, como a luta entre o capital industrial e a classe operária, e buscou inspiração percorrendo as ruas, os campos de mineração, infiltrando-se nas casas e na vida dos meios sociais menos favorecidos, tomando nota de tudo com o máximo de detalhes. Sem dúvida, podemos considerar o autor de Germinal como sendo o maior conhecedor da alma e da vida do proletariado francês do século XIX. Outra característica bastante acentuada do Realismo/ Naturalismo de Zola é a busca de critérios no empirismo das ciências naturais, tais como o princípio da causalidade, a ordem natural dos fatos, a eliminação dos acasos e milagres, a descrição fotográfica dos ambientes e a observação científica da realidade através do meio, da hereditariedade e do momento histórico.

Segundo Lílian R. Eurst e Peter N. Skrine (1971), o termo Naturalismo foi introduzido na literatura através das Beaus-Arts, certamente por Zola que, entre 1866 e 1896, manteve muitos contatos com o mundo artístico, ora como crítico de revistas especializadas, ora como companheiro de luta de seu amigo Paul Cézanne. O prefácio à segunda edição da obra Thèrése Raquin (1867), de Zola, marca essa passagem das ideias que afloravam no campo artístico para a crítica literária, ocasião em que ele adverte seus leitores sobre as suas intenções: "Em Thérèse Raquin, eu quis estudar temperamentos e não, caracteres. Aqui está todo o livro, eu escolhi personagens extremamente dominados por seus nervos e sangue, sem livre arbítrio, conduzido em cada ato de sua vida pelas mortes de sua carne." (1961, p. 08, tradução nossa).

$\mathrm{Na}$ arte impressionista a proposta era reproduzir mimeticamente a realidade (para isso saem dos estúdios e procuram o dinamismo junto à natureza) e observar as mudanças de um mesmo objeto de acordo com o jogo de luz e sombra e com o ângulo captado num determinado momento. A ligação entre a arte impressionista e a literatura realista-naturalista pode ser observada nas cenas de descrição em que o escritor se utiliza da técnica do Impressionismo para detalhar o objeto ou 
a paisagem em foco. Outra contribuição desse movimento artístico foi adotada, sobretudo por Zola que buscou inspiração na realidade, visitando os "temas" de suas obras com um caderno de anotações. Por fim, tanto os impressionistas quanto os realistas-naturalistas assumem uma visão pessimista e decadente da sociedade ao enquadrarem a classe dos menos favorecidos em suas obras.

\section{Stendhal e Tôson. Uma análise psicológica das personagens centrais Julien e Ushimatsu.}

Embora Kosugi Tengai tenha sido o pioneiro na produção de uma obra realista-naturalista no Japão, Hakai, de Shimazaki Tôson, foi o marco da entrada definitiva da teoria de Zola e do romance social francês. De uma maneira geral, a literatura francesa sempre esteve presente no círculo literário japonês do período Meiji (1868-1912) e sua divulgação só não foi maior devido aos problemas de tradução e ao número reduzido de japoneses que dominavam a língua francesa, razão que levou os nipônicos a tomarem contato com as obras francesas por meio de traduções inglesas. $\mathrm{O}$ fato de os literatos japoneses da época não terem "bebido diretamente na fonte límpida", isto é, não terem apreciado a leitura de obras francesas em sua língua de origem, não os impediu de assimilarem, por vezes de forma sutil e até inconsciente, as técnicas, o estilo e até a visão de mundo francesa. Essa presença se fez mais ostensiva no começo do século XX, mais especificamente, após a guerra russo-japonesa.

O momento histórico no Japão não poderia ser mais propício à introdução e divulgação dos pressupostos básicos do Realismo-Naturalismo francês. Após conquistarem a vitória no conflito contra a Rússia, os japoneses, que sonhavam romanticamente alcançar seus ideais, depararam-se com outra realidade bem distinta dos louros que imaginavam receber com a conquista. O clima era de desilusão e pessimismo entre a população que teve de aceitar as imposições do Tratado de Paz estipuladas pelas potências ocidentais. O desapontamento e o sentimento de injustiça levaram os japoneses a reverem alguns conceitos e a mudarem a sua visão de mundo; consequentemente, eles se tornaram mais céticos, objetivos e deterministas.

Comparativamente, o Realismo-Naturalismo francês também surgiu num momento de desilusão (após o fracasso das experiências políticas de 1830 e de 1848 , que apagou as chamas dos ideais de mudança social) e de tomada de consciência por parte dos revolucionários. É evidente que a situação histórica era bem distinta entre a França e o Japão no momento em que o Realismo-Naturalismo surgiu em cada um desses países; porém, guardadas as devidas proporções, pode-se dizer que os objetivos sociopolíticos eram muito próximos, na medida em que ambos lutaram pela igualdade de direitos. 
$\mathrm{Na}$ França, a luta foi interna a partir da revolta da classe proletária e dos pequenos burgueses (que haviam sido iludidos com as ideias da Revolução e de Rousseau), e que estavam cansados com a miséria e a injustiça da divisão de classes, ao passo que no Japão a revolta foi tanto interna quanto externa, pois apesar de o governo nipônico ter teoricamente abolido a divisão de classes na Constituição Meiji, a discriminação permanecia latente em muitos pontos. No nível internacional, os japoneses esperavam, com a vitória contra a Rússia, acertar o passo com as grandes potências ocidentais e desfrutar dos mesmos benefícios, o que não aconteceu.

Basicamente, é a partir desse ponto em comum, a injustiça da divisão de classes, que iniciaremos a análise do perfil psicológico dos protagonistas dos romances Hakai (1906), de Shimazaki Tôson e O Vermelho e o Negro (Le Rouge et Le Noir, 1830), de Stendhal.

A obra Hakai conta a história de Segawa Ushimatsu, um jovem inteligente que se muda para a pequena comunidade rural de Iiyama localizada ao longo do rio Chikuma na província de Nagano, onde passa a trabalhar como professor em uma escola primária. Logo Ushimatsu se torna muito popular entre os alunos e os colegas de trabalho. O drama reside na promessa, feita pelo rapaz ao seu pai, de nunca revelar a sua origem, ou seja, que pertence à classe dos eta ou burakumin. É necessário explicar que eta ou burakumin é uma classe social considerada abaixo dos mendigos e repudiada pelos japoneses. Embora a classe tenha sido oficialmente abolida em 1871, um vasto número de burakumin continua vivendo de forma segregada em guetos e comunidades fechadas (CANGIÁ, 2013). O heroi de Hakai vive uma tortura interna, sempre na iminência de revelar o seu segredo, como o único meio de salvação para o seu conflito. Na verdade, seu embate mental tem início ao ler a obra de Inoko Rentarô, um ativista que luta pelos direitos da classe eta. Por uma coincidência do destino, Ushimatsu acaba conhecendo Rentarô pessoalmente e sua admiração cresce imediatamente. Rentarô torna-se uma espécie de referência, símbolo de coragem e um herói na visão do protagonista. Ushimatsu sente grande vontade de revelar sua origem eta a Rentarô, mas o ativista é apedrejado até a morte por seus oponentes políticos. Após o incidente, Ushimatsu decide confessar aos seus alunos o seu segredo por meio de um longo e eloquente discurso em sala de aula. Embora tenha sido apoiado pelos estudantes, Ushimatsu estava consciente de que não poderia permanecer naquela cidade. Depois disso, Ushimatsu se muda para o Texas, nos Estados Unidos e estabelece uma colônia de agricultores japoneses no local, onde passa a trabalhar como professor.

Apesar das implicações políticas serem outras, estruturalmente a obra-prima de Stendhal também relata a história de um jovem inteligente de classe baixa chamado Julien Sorel que atinge, com muito esforço, certo destaque na sociedade (sempre ocultando o seu verdadeiro caráter ambicioso), sem, contudo, 
conseguir romper a velha divisão de classes entre a aristocracia e a plebe. Julien Sorel nasceu na pequena cidade de Verrières, no Franco-Condado, e era filho de um humilde carpinteiro. O rapaz de origem plebeia consegue infiltrar-se no mundo aristocrático francês, graças ao seu "pai intelectual", o cura Chélan que lhe oferece a oportunidade de trabalhar como preceptor dos filhos do prefeito da cidade, o Senhor Rênal. Ambicioso e sedutor, Julien acaba se envolvendo com a esposa do prefeito, a senhora Rênal, e depois de inúmeros percalços na relação, o rapaz decide abandonar a mansão. Muda-se para Paris e vai trabalhar como secretário na mansão do marquês de La Mole. Novamente, Julien tem um caso amoroso secreto, dessa vez, com a filha do marquês, Mathilde. O segredo é revelado ao pai quando Mathilde conta que está grávida de Julien. Apesar da fúria inicial, o pai resolve consentir o casamento de ambos, fazendo Julien entrar em êxtase, pois finalmente faria parte da alta sociedade. Contudo, seus sonhos são destruídos quando sua ex-amante, a senhora Rênal, conta ao marquês por carta que Julien era ambicioso e hipócrita. Julien, então, tenta matar a tiros a senhora Rênal, e em seguida é preso e condenado à morte.

Ambos os herois vivem num sistema tradicional, opressor, rígido e discriminatório, no qual o talento e a inteligência não são quesitos suficientes para se conseguir mobilidade e respeito social. Em Hakai notamos uma nova sociedade capitalista que conserva o pensamento do período Edo (1603-1868) e, da mesma forma, na obra de Stendhal constatamos um sistema capitalista não-liberal que conserva o método administrativo da velha aristocracia. Ambos, Julien e Ushimatsu, sentem desprezo pela classe dominante e guardam cada qual o seu segredo: Segawa, no papel de um pacato professor, esconde o segredo de sua origem eta, enquanto Julien, sob o manto do celibato, mantém em sigilo os seus sonhos de grandiosidade napoleônica. Ambos sofrem psicologicamente por não serem "bem-nascidos" e precisam enfrentar a dura realidade de que nunca poderão atingir a ascensão social por meios convencionais.

Ushimatsu e Julien, de certo modo, são personificações dos sonhos de grandes conquistas e de grandes decepções de toda uma época. No caso de Hakai, a Reforma Meiji representava uma esperança social de igualdade, uma nova organização política que iria proporcionar liberdade aos discriminados por seu nascimento; mas o tempo provou que as conquistas demoram a serem concretizadas em seu plano real. Já o povo francês do início do século XIX acreditava nos sonhos instigados pelas conquistas napoleônicas, mas após pouco tempo perceberam a inocuidade dessas glórias quando notaram que a divisão de classes não só permanecia, como também havia se fortalecido e que a nação francesa continuava seguindo a administração da velha Aristocracia.

Obviamente não colocamos num mesmo patamar os caracteres dessas duas personagens que, psicologicamente, agem de maneira até oposta. O heroi de Tôson 
tenta manter o seu segredo, por causa da promessa que fez ao seu pai e conserva, de alguma maneira, a sua integridade e o seu orgulho, isto é, mente para não sofrer discriminação, ao passo que Julien guarda o seu segredo para atingir a ascensão social e segue o caminho do celibato, não por vocação, mas porque sabe ser a única via de acesso para chegar aos seus objetivos. Não se importando com os meios utilizados para obter o sucesso, o protagonista de $O$ Vermelho e o Negro mostra-se altamente hipócrita nas relações humanas. Primeiro usa a sua falsa vocação religiosa como trampolim social, depois, como professor de latim e preceptor, aproveita-se da ingenuidade romântica da esposa de seu patrão, a senhora Rênal, para seduzi-la. Posteriormente, quando Julien vai à mansão do marquês de la Mole, na qualidade de secretário particular, o pequeno burguês usa a mesma fórmula de sedução e consegue conquistar a confiança do dono da casa e o coração de sua filha, Mathilde de la Mole, uma garota de dezenove anos, mimada, sonhadora e inexperiente. Enfim, Julien tenta explorar todas as oportunidades em seu benefício.

É interessante notar o desenvolvimento psicológico e emocional das personagens Ushimatsu e Julien. Ambos trabalham constantemente com o medo da revelação do segredo, da face oculta. Dessa forma, os narradores deram enfoque maior à sequência de pensamentos e emoções dos dois herois no decorrer dos acontecimentos, evitando, assim, as narrações dramáticas e situações incoerentes.

Tanto Julien, quanto Segawa podem ser considerados herois vencidos que, inicialmente, acreditavam que poderiam desempenhar na sociedade um papel de destaque de acordo com o seu talento e a sua inteligência, mas descobrem que todos os seus esforços são inúteis, pois estavam presos a um sistema social e político hermético, que não permitia grande mobilidade. Deparam-se também com a triste realidade de que o poder, no caso de Segawa, estava ainda nas mãos da tradição feudal e, no caso de Julien, da velha tradição aristocrática. Querem esquecer a sua origem inferior, mas não conseguem e são atormentados frequentemente com isso. Consideram a situação vivida por eles humilhante. Segawa encontra, como a única salvação dessa situação conflitante, a quebra da promessa e a revelação de seu segredo. Julien, por sua vez, com a revelação de seu segredo vê, como única salvação, a morte.

Outro ponto convergente entre os dois romances é que ambos foram baseados em casos reais. Stendhal teria se baseado no caso chamado Berthet, acontecido em 1827, com a execução de um criminoso, Antoine Berthet, que como Julien era de classe baixa, mas por influência de um cura tornou-se preceptor de uma família rica da cidade, seduziu a Senhora, virou amante, e depois precisou fugir. Ao mudar-se para Paris, foi ser preceptor em outra família, onde seduz a filha do Senhor. Não conseguindo seu intento de se casar com a filha que estava esperando um filho seu, por intervenção da antiga amante, Berthet vai atrás da ex-amante e tenta matá-la a tiros. Preso, é logo executado, aos vinte e cinco anos. 
Já Tôson parece ter se baseado na vida de Ôe Isokichi que nasceu em 1868, mesmo ano em que o Japão inicia seu processo de modernização e ocidentalização, deixando o passado feudal para trás. Ôe era membro do grupo minoritário eta, mas teve oportunidade de estudos e batalhou por uma vida mais digna longe dos estigmas de sua classe social. Contudo, apesar das reformas sociais instauradas no novo Japão, a população permaneceu presa em seus antigos pensamentos e preconceitos e Ôe acaba sendo vítima dessa discriminação.

Quanto à presença do Realismo/Naturalismo francês na obra de Tôson, constatamos certa influência de alguns pressupostos teóricos de Zola. Tôson sofreu influência de Kawakami Bizan que, consequentemente, o faria levar a Émile Zola. $\mathrm{Na}$ opinião de alguns críticos, Tôson não teve intenções de escrever um romance realista-naturalista e a única influência recebida por Zola teria sido em relação à sua preocupação em buscar um romance verdadeiro, com a descrição objetiva da realidade. Contudo, a nosso ver, colocando à parte o caráter tecnológico e científico, Hakai pode ser considerado um romance realista-naturalista na verdadeira concepção da palavra.

Podemos afirmar que, em primeiro lugar, Zola e Tôson trabalham com as figuras que vem das camadas sociais menos favorecidas, o povo propriamente dito é a fonte de inspiração desses escritores. As personagens perdem a individualidade para representarem uma classe - dos eta e dos proletários -, pois o que interessa são os conflitos de classes. Em segundo lugar, ambos acreditam na importância do estudo de campo para a descrição objetiva da realidade. Zola costumava viajar aos locais, com um caderno de anotações, para poder sentir melhor a realidade de seus temas, ambientar-se com os fatos e realizar uma análise microscópica do local. Da mesma forma, Tôson procurou essa objetividade ao viajar em 1899 para a cidade de Komoro, onde passou sete anos fazendo anotações e trabalhando como professor primário. Em terceiro lugar, Tôson e Zola acreditam no princípio da hereditariedade e da influência do meio como condicionador das atitudes e das qualidades do indivíduo. Em Hakai, Ushimatsu nasceu eta, portanto, ele pertencia a essa classe independentemente de sua vontade, a sua condição social fora herdada e não há como escapar disso. Na vida real, Shimazaki Tôson viveu uma situação semelhante à de sua personagem, quanto à questão da hereditariedade. $\mathrm{O}$ pai do escritor, no final de sua vida, revelou-se insano, fato que Tôson tentou omitir perante a sociedade com medo de sofrer algum tipo de discriminação; entretanto, o seu receio maior era o de que a doença do pai estivesse em seu sangue.

É importante acrescentar que a vitória na guerra russo-japonesa, certamente marcou a aceitação e o crescimento do movimento Naturalista no Japão que floresceu entre 1906 e 1910. Para Donald Keene, esse fato "não foi acidental" (p. 220). O mundo todo havia subestimado a força do Japão, um pequeno país recém-saído do período feudal, mas que, mesmo após ter provado o seu poderio e a sua 
capacidade bélica, não conseguiu atingir todos os seus objetivos e entrar para o círculo das grandes potências ocidentais. A euforia da vitória seguida da decepção foi denominada pelos japoneses como o "Ano da Desilusão". A obra Hakai, de Tôson parece lançar esse mesmo olhar de entusiasmo por uma possível mudança seguida imediatamente de uma grande decepção, na qual apesar das virtudes irrefutáveis de um indivíduo como Ushimatsu, ele estava fadado ao determinismo de sua hereditariedade. Tôson lança, igualmente, a ideia de estereótipo de uma classe ou raça inferior em Hakai. As pessoas da comunidade, que acreditavam que os membros da classe dos eta eram sujos e sem capacidade intelectual, ficam surpresos ao saberem que Segawa, um homem talentoso e inteligente, era um eta.

Apesar de Hakai ter evidências de um romance social, é necessário esclarecer que o autor não teve o desejo de escrever um panfleto sociológico. Em um ensaio escrito em 1928, Tôson revela que o significado de seu romance Hakai está na relação intrínseca entre pai e filho e que seu interesse pela classe eta não é propriamente por sua faceta social, mas, psicológica; pois seu romance revela um retrato psicológico vívido de seu heroi, cujos conflitos mentais eram constantemente narrados em forma de exame de consciência, pressão social, sonhos e medo da revelação (KEENE).

Stendhal também traça um perfil psicológico bastante complexo de seus personagens e, por essa razão, acabou recebendo de Taine o título de grande romancista e o maior psicólogo do século (ZOLA, 1995). Zola também partilha da mesma opinião e arremata afirmando que:

\footnotetext{
Stendhal é antes de tudo um psicólogo. Taine definiu muito bem seu domínio, dizendo que ele se interessava unicamente pela vida da alma. Para Stendhal, o homem é composto apenas de cérebro, os outros órgãos não contam. Situa, evidentemente, os sentimentos, as paixões, os caracteres, no cérebro, na matéria pensante e agente. Ele não admite que as outras partes do corpo tenham influência sobre esse órgão nobre, ou pelo menos essa influência não lhe parece de modo algum bastante forte nem bastante digna para que nos inquietemos com ela. (Idem, p. 57)
}

Retornando à relação entre pai e filho, destacada por Tôson, encontramos também na obra de Stendhal uma forte conexão entre Julien e seu pai, entretanto, ao contrário de Ushimatsu, trata-se de um relacionamento conturbado, abusivo e perturbador que nos leva a compreender a natureza dos pensamentos e do caráter do protagonista. Julien seria um filho de orgulho numa família aristocrática: inteligente, fino, estudioso e ambicioso; entretanto fora pré-determinado pelo destino a ter um pai ignorante. $O$ pai Sorel era um homem bruto que não aceitava um filho sensível com inclinação à cultura, o que fez de Julien uma máquina de ambição e hipocrisia. A imagem de um pai ambicioso e castrador levou Julien a também olhar o mundo de forma material e oportunista. Julien ainda demonstra uma ausência 
afetiva em consequência à educação rude que recebeu como notamos no diálogo abaixo com o pai:

- Responda-me sem mentir, se pode, cachorro de leitura; de onde conhece a Sra. de Rênal, quando falou com ela?

- Nunca lhe falei - respondeu Julien - Nunca vi esta senhora senão na igreja.

- Mas você olhou para ela, vilão descarado?

- Nunca! O senhor sabe que só vejo Deus na igreja - acrescentou Julien, com um arzinho hipócrita, próprio, segundo pensava, a afastar o retorno das pancadas.

(STENDHAL, 2003, p. 21, grifo nosso)

Já no caso de Ushimatsu, o papel de seu pai foi de protetor no processo de formação de seu filho. Parece natural que um pai queira o melhor para o seu filho em termos de saúde, educação e profissão, porém para o pai de Ushimatsu desejar isso e tentar promover o bem-estar do filho eram duas coisas bem distintas por conta de sua origem eta. O pai de Ushimatsu projetou em seu filho tudo aquilo que julgou como sendo o melhor para ele, no entanto, apesar de sua intenção sublime de cuidador, ignorou a natureza sensível de seu filho. Se Ushimatsu pai tivesse espreitado melhor a personalidade de seu filho, certamente saberia que ele não seria capaz de guardar tal segredo.

Tôson não pertencia à classe eta, porém também ocultou por longo tempo o fato de seu pai ter morrido insano. Como foi dito anteriormente, o grande medo de Tôson era que a doença de seu pai fosse hereditária e que as pessoas passassem a discriminá-lo por isso. Ao que parece ao focar a relação pai e filho no romance Hakai, Tôson transferiu a sua própria problemática ao protagonista, daí a sua declaração no ensaio de 1928.

Por fim, resta dizer que os dois romancistas encontraram uma solução literária conveniente para os respectivos epílogos. Em Hakai, inesperadamente, nos deparamos com um "final feliz", atípico dos romances naturalistas; entretanto sabe-se que muitos membros da classe $e t a$, na vida real, procuravam na emigração uma solução para os seus problemas de discriminação. Já em $O$ Vermelho e o Negro, o final trágico é condizente com o senso de justiça da vida real. Julien passa de jovem ambicioso e hipócrita para assassino vingativo. Enfim, dar outro desfecho ao romance de Stendhal seria, no mínimo, irrealista, para não se dizer impróprio ao contexto histórico vivido pelo autor.

\section{Referência bibliográfica}

AUERBACH, Erich. Mimesis. A representação da realidade na literatura ocidental. São Paulo: Edusp/ Editora Perspectiva, 1971. pp. 395-458. 
CANGIÁ, Flávia. Performing the Buraku. Narratives on Cultures and Everyday life in Contemporary Japan. Berlin: Lit Verlag Dr. W. Hopf, 2013.

CARPEAUX, Otto M. O Naturalismo. In: História da literatura ocidental. A época da classe média. Vol. V. Rio de Janeiro: Edições O Cruzeiro, 1963. pp. 2261-2447.

CLAUDON, Francis \& HAADAD-WOTLING, Karen. Elementos de literatura comparada. Teorias e métodos da abordagem comparatista. Sintra: Inquérito, 1992.

EURST, Lílian \& SKRINE, Peter. O Realismo-Naturalismo. A linguagem crítica. Tradução: João Pinguelo. Lisboa: Lysia, 1971.

GLUNCK, Carol. Japan's modern myths. Ideology in the late Meiji period. New Jersey: Princeton Universtiy Press, 1985.

HAUSER, Arnold. História social da literatura e da arte. V. II. São Paulo: Editora Mestre Jou, 1971.

KATAI, Tayama. Literary Life in Tokyo. Literary life in Tōkȳ̄, 1885-1915: Tayama Katai's memoirs "Thirty years in Tōkyō." Translated and introduced by Kenneth G. Henshall. Brill, 1987.

KEENE, Donald. Dawn to the west. Japanese literature of modern era. Fiction. New York: Holt, Rinehart, and Winston, 1984.

KUNITOMO, Tadao. Japanese literature since 1868. Tokyo: The Hokkuseido Press, 1938.

MITTERAND, Henri. Zola (la vérité em marche). Paris: Découvertes Gallimard Littérature, 1995.

STHENDAL. O vermelho e o Negro. Tradução: Maria Cristina F. da Silva. São Paulo: Editora Nova Cultural Ltda, 2003.

TÔSON, Shimazaki. The Broken Commandment. Tradução: Osuke Shimazaki. Tokyo: University of Tokyo Press, 1990.

WEBER, Eugen. França fin-de-siècle. Tradução: Rosaura Eichenberg. São Paulo: Companhia das Letras, 1988.

ZOLA, Émile. A batalha do Impressionismo. Tradução: Martha Gambini. Rio de Janeiro: Paz e Terra, 1989.

Do romance: Stendhal, Flaubert e os Goncourt. Tradução Plínio Augusto Coelho. São Paulo: Editora Imaginário, Editora da Universidade de São Paulo, 1995. 